\title{
CERN: Guardian of the Human Aspiration to Understand the Universe
}

\author{
Jos Engelen and Paul 't Hart
}

\section{High Modernity in Geneva}

The campus of the European Organization for Nuclear Research, known the world over as CERN, does not immediately light a spark in those who visit it. The visitor centre does impress with dynamic visual displays of space, matter, movement and energy. But it is not until one is taken underground deep below the Geneva countryside and into the organization's current crown jewel, the Large Hadron Collider, that the lure of the endeavour becomes irresistible. It is like that moment about twothirds into any James Bond movie, when Bond is being led-often at gunpoint - into the villain's subterranean headquarters and encounters a hidden world of shafts, staircases, miles and miles of electrical cables, gigantic machines, control panels, busy technicians in overalls and focused scientists donning hardhats.

J. Engelen

University of Amsterdam, Amsterdam, The Netherlands

e-mail: engelen@nikhef.nl

P. 't Hart $(\bowtie)$

School of Governance, Utrecht University, Utrecht, The Netherlands e-mail: p.thart@uu.nl

(C) The Author(s) 2021

A. Boin et al. (eds.), Guardians of Public Value, https://doi.org/10.1007/978-3-030-51701-4_9 
It is a captivating spectacle. Indeed, as one observer put it, '[ $t]$ he idea of accelerating subatomic particles to almost the speed of light, and smashing them into each other deep under the French and Swiss countryside, has a Bond-villain grandeur that has manifestly caught the public imagination' (O'Neill 2008). It is in these bowels of the Large Hadron Collider that one sees CERN's craft epitomized: high science being put to work to comprehend the origins and dynamics of the universe.

The official name of this organization-Conseil Européen pour la Recherche Nucléaire (CERN) - does not reflect what it does. No nuclear fusion or fission is attempted there. It is not in the business of generating energy, let alone building weapons of mass destruction. CERN is best described as the world's most formidable centre for particle physics. Its mission is radically ambitious: uncovering what the universe is made of and how it works. CERN hopes to achieve that mission by providing particle accelerator facilities that enable world-class research in fundamental physics, bringing together scientists from all over the world to push the frontiers of science and technology. Having made discernible progress on its mission over the course of the past half-century, it has become widely recognized as one of the most successful cross-national collaborative research organizations of all times.

CERN is a European organization with permeable boundaries that has developed into the undisputable hub of a global network of scientists without peer. The CERN Community, both at its Geneva campus and its many tentacles in research institutes around the world, has invented and built the capacity to sift through many billions of particle collisions and detecting promising patterns among them. CERN's Data Centre is widely regarded as pioneering the future of computing, with very large quantities of data-about $1 \%$ of daily global data traffic-being continuously analysed through seamless connectivity to 170 other data centres in 36 countries (Cogen 2016). CERN has gifted its most renowned spinoff technology - the World Wide Web - to the world for all to use (Gillies and Cailliau 2000).

To get to this point, CERN has managed to resolve the existential political conundrum that plagues most large-scale public endeavour (see Schulman 1980). For more than six decades it has managed to straddle the inevitable gap between the requisite multi-year up-front investment of money, infrastructure and human effort, and the eventual accomplishments that make everyone feel it has all been worthwhile-in its case scientific breakthroughs in the world of particle physics. 
As we will show in this chapter, CERN is without a doubt to be considered an institution as defined in this volume and yet it is an unlikely organization to achieve this lofty status. Its mission is elusive and it has no preordained path to achieve it; in fact, the whole point of its mission is to discover such pathways towards new knowledge of the fundamental particles and forces that govern nature at the deepest level, which demands incessant, vast, costly experimentation. It is a multinational endeavour that requires physicists to collaborate on an even keel with engineers and, even more challenging, with government bureaucrats from almost two dozen member states. As an intergovernmental organization it has to navigate geopolitical complexities, diplomatic challenges and misalignment between the organization's needs and the political and budgetary realities of its member state funders.

Its unparalleled analytical capability has enabled CERN's scientists to achieve its greatest deliverable so far: the discovery of the Higgs boson particle. The jewel in the crown of the Standard Model of Physics, it had been the last hold-out particle remaining hidden during the quest to check the accuracy of the Model which describes three out of four fundamental forces (not covering gravitation) in the universe and classifies all elementary particles known to man. The Standard Model has become 'the most accurate scientific theory known to human beings' (Starkman 2018) and the discovery of its hitherto only hypothesized linchpin, the Higgs boson, validated more than a generation of scientific endeavour within particle physics.

CERN has been able to thrive, we argue, by evolving a particular mode of harnessing human ingenuity: overcoming the fault lines and centrifugal forces that inevitably arise between the various parties involved. CERN as a cooperative venture has been driven by a sense of interdependence, entrenched norms of mutual respect, trust, empathy and consensual decision-making. CERN's ethos is one of transparency and knowledge sharing. Its governance has been far-sighted. It has delivered scientific advances, technological breakthroughs, spinoff technologies and a thriving global scientific community. It has been able to do so on the wings of consistent support from member state governments and favourable media coverage. Robinson (2019: 48), who studied its governance up close, observes that

CERN has an unchallenged standing of legitimacy and enjoys a shared set of normative and principled beliefs, shared causal beliefs, shared notions 
of validity and a common policy enterprise throughout its epistemic community.

The thriving development of CERN, continuing for over 65 years, is best described as a combination of a smart institutional design, good governance, resourceful leadership and resilient collaboration. This powerful mix provides the spring board for the astute adaptation and dogged determination that allow CERN to sustain its performance. But in the beginning, this was all far from certain. This chapter tells the story of how CERN got to where it is today. We will explore what constellation of circumstances, choices and practices has allowed it to become and remain a global science institution. Moreover, we will examine CERN's future in view of the growing tension between the size and duration of requisite investments and the uncertainty about if and when it will deliver its next piece of magic.

\section{Working on a Dream: BuILding CERN}

CERN was founded in September 1954. Its roots lie in two sweeping developments. One was the coming together of scientific aspirations to move beyond the state of the art of mid-twentieth-century physics. Another was the cooperative spirit that pushed diplomats, businessmen, academics and other elites towards greater unity among the countries of Europe in the wake of the Second World War. Acting against the gloomy backdrop of the escalating Cold War which was dividing the continent, this informal but influential network saw that science had a crucial role to play in doing so. At their instigation, leading French quantum physicist Louis de Broglie had an address delivered in his name to the first Conference on European Culture, hosted by the Swiss writer and promotor of European federalism Denis de Rougemont in Lausanne in December 1949. He observed that

[A]t a time when we are talking about the peoples of Europe, the question now arises of developing [a] new international unit, a laboratory or institution where it would be possible to work scientifically in a manner outside and above the framework of the different participating nations. As a result of the cooperation of a large number of European States, this body could be endowed with more resources than those available to national laboratories and could subsequently undertake tasks which by virtue of their size 
and costs remain prohibitive to these [national laboratories]. (quoted in Gillies 2018: 12)

De Broglie was talking about scale. The need for resource-pooling proved a powerful rhetorical tool for the advocates of an advanced European physics laboratory. Robinson (2019: 43) notes that eventually:

Consensus to form CERN was reached through the timely and powerful combination of ... European-minded politicians and single-minded European particle physicists. The politicians were looking for practical ways of reorienting Europe and the physicists were looking for their facility.

It was a case of scientific idealism challenging scientific realism. The Manhattan Project and the race to develop ever more powerful weapons of mass destruction that was taking shape in the early post-war years were the palpable developments against which De Broglie and a core group of academic colleagues from around Europe sought to cast the new European scientific collaboration. CERN was to be a purely scientific venture and not to engage in military R\&D. It was to be genuinely European and thus not dependent upon collaboration with the United States (where influential fellow physicists such as Isidor Rabi helpfully lobbied for the cause of European physics). And it was rooted in the recognition that the cash-strapped impoverished nations of Europe could only hope to do something worthwhile in this high-investment area of scientific research if they were going to pool their resources. It took De Broglie, Rabi and other scientific champions another five years of advocacy and deft manoeuvering of the geopolitics of science-particularly in a sensitive field such as 'nuclear' research-before there were enough signatures on the intergovernmental convention document establishing the new institute.

\section{The Early Years: Overcoming Challenges}

The early decades that followed its founding were not easy. CERN was a 'shell organization', with a name, a site, a budget, a formal governance structure, a dedicated group of foundational leaders and a rump staff. It was many years away from being in a position to deliver the kind of scientific breakthroughs it aspired to bring about. A study of the early years of CERN's institutional development shows how during its first decade and 
beyond, the organization was struggling to find its feet. It was dealing with several challenges.

First and foremost, the scientists and non-scientists (science administrators from the member states) had to learn to get along. Trawling through the paper trail of memos, minutes and reports from those early years, Pestre (1988: section 9.1.2.1) notes that despite the overall atmosphere of goodwill and mutual respect, various forms of 'incomprehension or of denigration' lurked in the background, ready to surface when there were tensions about budgets, priorities and allocation of contracts for the construction of facilities and equipment:

$\mathrm{Th}[\mathrm{e}]$ esteem which the scientists have [for the non-scientists on the CERN Council and in key committees, see further below] is never blind, is never as total as it appears to be between the members of the physics clan themselves. It is limited precisely because the 'politicians' are not, after all, high-energy physicists... [T] his is sometimes expressed in ... a measure of condescension towards the non-scientists - and notably he 'politicians', those who stop them from doing their job properly, who always introduce unnecessary complications, who never grant even the budgetary minimum without looking sour, without bickering - and who want to control.

In their efforts to persuade 'the politicians', the scientists regularly resorted to 'offensive selling' of their projects and their budgetary claims:

Since CERN always had to act quickly - CERN was to be the first in the world [to achieve this or that scientific or technological milestone] - and since CERN had to have the best men and the best equipment, it was always easy and tempting to present the 'politicians' with a fait accompli, ... [making] abundant use of the argument that things were 'urgent' and top priority. (Pestre 1988: section 9.1.2)

Likewise, to obtain decisions from the CERN Council, CERN's scientific leaders regularly invoked the threat of losing out the physics race to the Americans, with their massive science community and post-World War II opulence and momentum. The civil servants serving on the Council and its Finance Committee, who had to straddle the mandates provided to them by their national government superiors and the desire to be seen to be a constructive partner in the great cooperative venture envisaged by the scientists, found it hard to challenge their claims. 
Secondly, not all European physicists were internationalists. While subscribing to the general idea of a joint facility, they also kept in mind and promoted the interests of their own research programs, their own teams, their own labs back home. This guarded posturing was prevalent in the early years when CERN had not yet proven its worth and had not yet delivered on its aspiration to become the hub of the European high-energy accelerator fraternity. And there were the British, who were fundamentally ambiguous about what really was in it for them, given that they had made significant advances in particle physics on their own during and following World War II.

Third, CERN's governance structure-which envisages a balance of power between the (supranational and scientifically driven) DirectorGeneral and the elite scientists whispering in the DG's ear on the one hand, and the (intergovernmental and policy-driven) Council on the other-had to settle in. The CERN-based actors sought, and by and large managed, to keep national bureaucracies at arm's length and gain a measure of autonomy in setting directions for the institution. Pestre (1988: section 9.1.3.1) characterizes the early governance of CERN in terms of a 'jealously guarded autonomy of the Council' and machinations of a 'pro-CERN lobby at its heart' designed to 'neutralize' any initiative from any of the member state authorities seeking to bypass it.

Fourth, there were protracted and heated discussions about CERN's internal management. The early Director-Generals, particularly Cornelis Bakker (1955-1960) and Victor Weisskopf (1961-1965) faced the challenge of herding cats, with powerful divisional directors such as the head of the synchrotron division (and future director) John Adams looking to build their autonomy. There were constant proposals and debates about internal organization, which were essentially about where the power of policy initiative and investment decision-making would come to lie in the organization, and how accountability for policies and expenditures was to be organized.

\section{Achieving Momentum}

It was not until the early to mid-1960s that the incentives for commitment to this form of international scientific cooperation started to kick in. In 1959, CERN's first major common pool resource, the proton synchrotron-then the world's highest energy particle acceleratorbecame available. Many high-profile experimentalist physicists began to 
use it, which cemented commitment to CERN beyond its close-knit founding community. It was a watershed moment, laying the foundation for what became the politically impenetrable fortress of scientific collaboration that CERN has since become:

Not constituted from above, by a juxtaposition of delegates nominated administratively by the states..., the central core of the Council built itself up in the course of a battle which lasted several years. From these beginnings an unusual degree of cohesion was born, along with a determination to succeed, which bore fruit thanks to the favourable context in which it emerged, the context of a Europe looking for ways to unite, and fascinated by all that was nuclear... Once the leaders of European nuclear physics realized, early in the 1960s, that there was no alternative to building a central installation for the ever-heavier equipment their science demanded, and once they accepted that this installation would be CERN, they no longer submitted their national authorities to conflicting pressures... Speaking with a single voice to the exterior, they ensured the continued good health and the success of the organization and left the member states watching developments from afar. (Pestre 1988: section 9.1.4)

Fast forward fifty years and a picture of a settled institution and a cohesive science community emerges. A series of landmark achievements demonstrated the added value of the collaboration across disciplinary and national boundaries. The institution leans on decades of 'identity work' to ensure that the constant flow of new and eager scientists come to regard CERN as not just a tool to be used but as a place that confers identity and respect on them. Here we see a virtuous cycle. A deep sense of commitment and loyalty feeds into high performance by virtue of CERN's ability to continuously attract top staff and make them work together to achieve both scientific advances and tangible, brand-enhancing outcomes:

The combination of ... high scientific and political standing, ambitious forward-looking research programme, independence as a supra-national organisation [and] cash-based finances results in an ability to recruit and retain very competent staff. As an established international organisation... CERN is able to offer attractive employment conditions (salaries, pensions, etc.). The staff form an interacting community characterised by a vigorous exchange of ideas. At times, ideas emerge that can be transformed into innovative new technologies, even commercial products. (OECD 2014: 64) 


\section{How CERN Is Governed ANd Managed}

Robinson (2019) identifies a range of what he calls 'mechanisms' that are embedded in CERN's institutional design that have allowed it to overcome the threat of gridlock that besets any multilateral collaborative endeavour. The pathways in the left-hand column of Table 9.1 refers to Hale and Held's (2017) theory of gridlock-busting factors. The righthand column then details to which extent and in which forms these factors can be found within CERN. Let us now take a closer look at what lies behind these mechanisms.

\section{Smart Institutional Design}

The 1953 Convention articulates CERN's mission and institutional design. It offers a sense of purpose and ground rules for governance that have stood the organization in good stead. It is crystal clear about what CERN is to be and not to be. The Convention explicitly instructs all staff to work without fear or favour for the benefit of the international, collaborative entity that CERN is and not to be influenced by preferences, demands and hints from any of the member states or other research institutes. The Convention stipulates that the fruits of all its work should be made publicly available.

The Convention also limits CERN's activities to scientific collaborative research on high-energy particles, laying down clear boundaries and norms for how it is to pursue its activities: 'The Organization shall have no concern with work for military requirements and the results of its experimental and theoretical work shall be published or otherwise made generally available' (Convention 1953, Article II,1). A former directorgeneral notes: 'The spirit from the beginning, was that we are not at CERN to profit; we are there to help to achieve the common objective. A principle introduced by the founding fathers that still exists today' (quoted in Robinson 2019: 43).

This clear delimitation of CERN's mission-no military pursuitsprovides the Council with a key lever to check on mission creep and ensure the coherence of resource allocations without stifling innovation in how CERN researchers pursue the mandate. The CERN Council is the supreme authority of the organization. Appointed by the Council for a single 5-year term, the Director-General leads the CERN Laboratory on a day-to-day basis, supported by a senior management team called the 
Table 9.1 Pathways to effective international collaboration: the case of CERN

Pathway CERN community mechanism

1. Shifts in major powers' core interests

- Catastrophic Second World War led to incentivisation for States through the European Movement and embryonic UNESCO to combine with visionary European particle physicists to create the Organisation

2. Autonomous and adaptive international institutions

- Governing bodies have been given inimitable capabilities to adapt to emerging issues and shifting constellations of power and interests

- Member States have one vote each in Council; the primacy of the State is sacrosanct

- Science Committee members are elected solely on merit by peers and are independent of national and/or other institutional affiliations

3. Technical groups with effective and legitimate processes

4. Multiple, diverse organisations and institutions coalesce around common goals/norms

- Experiment team's authority comes from intellectual contribution and consensual decision-making; project adhocracy and trust in the workforce leaves teams of experts to solve complex problems in whatever manner they see fit

- The name 'CERN' is synonymous with the very best scientific research standards, execution and

delivery

- Unmatched global reach: over 12000 researchers from institutes in over 70 countries being actively engaged

- World-wide connectivity with very large quantities of data being continuously analysed through seamless connectivity to 170 other data centres in 36 countries

- Centre of excellence for holding of global fundamental physics seminars, conferences and events 
Table 9.1 (continued)

\begin{tabular}{|c|c|}
\hline Pathway & CERN community mechanism \\
\hline 5. Mobilisation of domestic constituencies & $\begin{array}{l}\text { - The data confirmed that these two } \\
\text { Beyond Gridlock pathways do not fully } \\
\text { feature }\end{array}$ \\
\hline $\begin{array}{l}\text { 6. Civil society coalitions with reformist } \\
\text { states }\end{array}$ & \\
\hline $\begin{array}{l}\text { 7. Innovative leadership as a reaction to } \\
\text { gridlock }\end{array}$ & $\begin{array}{l}\text { - Leadership is characterised by } \\
\text { inclusivity and equality of contributing } \\
\text { disciplines in terms of voice and status } \\
\text { - Leadership has an aura of invincibility } \\
\text { within the global fundamental physics } \\
\text { community. A reputation borne out of } \\
\text { its repeated scientific successes and its } \\
\text { ability to overcome obstacles, threats } \\
\text { and set-backs by fair, timely and } \\
\text { consensual governance } \\
\text { - See }(3) \text { above for leadership of } \\
\text { technical teams }\end{array}$ \\
\hline 8. Innovative Funding & $\begin{array}{l}\text { - Scrupulously fair funding formula } \\
\text { based on Member State economic } \\
\text { strength for annual cash contributions } \\
\text { - Procurement protocols help maintain } \\
\text { alignment of work share to } \\
\text { contributions but are not bound by } \\
\text { strict 'juste retour' } \\
\text { - Experiment projects are effective } \\
\text { collaborations of in-kind contributions }\end{array}$ \\
\hline
\end{tabular}

Source Robinson (2019: 50)

Directorate. Below them operate a series of departments. All major policy and funding decisions require Council approval. The Council controls CERN's activities in all matters scientific, technical and administrative. It approves programs of activity, adopts the budgets and reviews expenditure. Each of the 23 member states has two delegates on the Council: one science administrator and one leading scientist.

The Convention provides for a 'one member, one vote' decisionmaking mechanism within the Council, thus steering CERN's governance away from the politics of (financial) weight that plague so many other intergovernmental organizations (Goetz and Patz 2017). This mechanism creates a stable, level-playing field and has survived the growth of the 
organization from 12 to 23 member states (late 2019) and the attendant differentiation of member state resources and capabilities.

Most Council decisions require a simple majority, but some, such as the appointment of a new director-general, require two-thirds majorities. In practice, the Council reaches decisions by consensus and strives for unanimity. The Council is supported by two pivotal advisory committees: the Scientific Policy Committee and the Finance Committee. The Scientific committee is composed of top scientists regardless of nationality who are elected into membership by their peers on the committee. The Finance Committee consists of technical experts from the member states and mainly focuses on matters related to financial contributions.

In Robinson's (2019) fieldwork at CERN, many long-serving staff voiced how proud they were of 'their' Convention as a document that sets the scene for fostering international collaboration and provides a healthy balance between top-down and bottom-up management approaches. As one interviewee granted: 'we owe a lot to our founding fathers both on the scientific side and wise people in the ministries and governments at that time who made that happen' (Robinson 2019: 43).

\section{A Conducive Culture}

CERN's leading figures embraced the norms of collaboration, trust, transparency early on. As an example, the internal norm became that of individual but collective authorship of papers, both within as well as, when pertinent, across the collaborative experiments. This has meant alphabetically listing all members of a collaboration as authors on any paper written based on data from that project by any member of that collaboration. As a result, some CERN papers ended up having over 500 authors. Though not without difficulties and trade-offs for the career choices of the individuals involved (Birnholtz 2008), this norm of credit-sharing helped the CERN circumnavigate most of the credit-driven professional competition and rivalries between individual researchers and groups within the organization that have such a debilitating effect in many other laboratories and research groups in the academic world.

CERN's institutionalization owes a lot to the way in which it has evolved norms and practices of balance-seeking. Balance between funding member states and the spending CERN administrators. Balance between small and large contributors. Balance between centralized lab and infrastructure funding and bottom-up funding of the experiments. Balance 
between getting on with current work and preparing the ground for taking on new challenges and realizing future ambitions that may be decades away. Balance between the scientists' advances in fundamental physics and the engineers' development of the technological tools required to test them. Balance between running a tight ship financially and maintaining the ability to respond flexibly to financial setbacks or emerging expenditures. Balance between the patience required to achieve major scientific breakthroughs and the need to be seen to be active, relevant and impactful now, which is critical to maintaining a global public and political support base. Balance between banking on the authority of established scientific leaders and empowering the innovative irreverence of emerging research talents.

Such balancing is necessary to prevent the twin dangers of gridlock and mission creep (Selznick [1957] referred to conservatism and opportunism). The conditions for a balanced institution must be created in its organizational structure and nourished through its organizational culture. Take the 'power distance' (Hofstede 1991) between the established 'Godprofessors' and next-generation budding talents. In its examination of the economic and societal impact of CERN, the OECD (2014) paints a picture that epitomizes what Goodsell (2011) considers a 'prime quality' of public institutions: its official truths are open to contestation because this power distance is actively kept within bounds. Here's what the OECD (2014: 65) reports about CERN:

\begin{abstract}
All large research institutions are necessarily hierarchical organisations, with well-defined structures and procedures for ensuring responsibility, accountability and reporting. CERN's version of the hierarchy is relatively "flat", especially where it concerns communication and interaction across the vertical dimension of the hierarchy. It is not unusual for junior members of the staff, or researchers from collaborating institutions (even graduate students) to "buttonhole" the senior laboratory leaders in order to present original ideas or opinions. In part, this is a consequence of the inherently meritocratic nature of scientific research but, at CERN, it is reinforced by the special status of the laboratory that sets it apart from traditional institutions.
\end{abstract}

Another good example is the funding regime. Its ingenuous architecture is a key source of CERN's strength. It provides a solid central base funding but allows no one to get 'fat' and complacent. It incentivizes entrepreneurship and coalition-building among staff members, 
research institutes and nation states while hedging against excessive risk accumulation:

Countries contribute to a central fund for the infrastructure of the lab as a whole. However, while the infrastructure of the lab comes from the pooled fund, the experiments do not. This means that while the Large Hadron Collider (LHC) was built by CERN using the money contributed to the central fund, the four giant detector experiments were funded, designed, and built by independent collaborations of nations. This way, if one falls behind, it doesn't necessarily mean the entire project will suffer. (Lucibella 2014)

The funding regime spreads the load fairly among member states; their contributions are pegged to (developments in) their GDP. If times are lean in a particular member state, its representatives in the Council do not face pressure to go home and fight unwinnable budgetary battles with their science and treasury departments in order to maintain a set contribution amount. Moreover, as critical episodes involving budgetary and political turbulence in the United Kingdom and then Germany in the 1980s and 1990s have shown, there is a collective norm of empathy and a propensity for pragmatic long-term thinking within the Council and in CERN's Directorate and Finance Committee. This leads them to respond flexibly to the budgetary and political exigencies of the moment by accommodating the predicaments of certain member states through collective burden-sharing. Grand as it may sound, particularly when it comes to the politics of budgetary processes within publicly funded organizations, fairness, empathy and adaptability are demonstrably built into the fabric of CERN's decision-making structures and the rules by which they operate.

\section{The Importance of Leadership}

CERN would never have existed but for the visionary leadership of its founders. In the late 1940s and early 1950s, leading physicists such as De Broglie and Rabi gelled with diplomats and other promotors of European cooperation to argue the case for transnational science collaboration. To persuade not just small states (who had nowhere else to go anyhow) but also Europe's major powers France and Great Britain (whose geostrategic preferences and academic chauvinism might otherwise have led them to 
turn against participation in a joint enterprise) and their World War 2 opponents Germany and Italy to partake in this coalition was a major coup of academic entrepreneurship and diplomatic ingenuity.

Also, the sheer stability of its scientific and administrative leadership cadres in the critical early years of the organization has proved an important factor. During the first fifteen years of its lifespan the Council was dominated by a core group of men-they were all men-of the first hour who had held key positions in CERN and/or were representatives of countries that carried weight. The same goes to a large extent for the Scientific Policy Committee. This stability at the core helped to create interpersonal trust between these institution-building leaders. It helped them to contain centrifugal forces and deal with emerging conflicts pragmatically. These members of the institution-building generation took up their roles in a particular way: they were not acting as national gatekeepers but as ambassadors for the organization within their respective constituencies (Pestre 1988).

Furthermore, with multiple power centres and multiple balancing acts between constituencies, carrying different values and interests, an organization like CERN can only be steered and adapted through a form of dispersed leadership (Verbeek 2009). Over the decades, a now entrenched form of power-sharing has developed between Directorate, Council, the committees, the divisions the experimental collaborations. The rules of engagement provide a conducive setting in which individual and teams of scientists can 'do their thing', yet within parameters and levels of resourcing and accountability that are negotiated and determined in the interplay between the key institutional nodes in the governance structure. The Director-General is the face of the organization in the world outside CERN, and an influential authority figure within it, but cannot and will not impose major policy decisions on the system. Smooth relationships between DGs and Council presidents are essential for greasing the wheels of the relationship between the core executive team (the Directorate) and its 'board of directors' (the Council).

Finally, in a science organization such as CERN it is pivotal that a significant share of the leadership structures and processes are animated by professional authority figures, whose leadership claims are rooted in substantive expertise and peer esteem rather than managerial qualities or political networks. CERN is not run solely by 'administrators', far from it. There is a large and vocal community of scientists that jealously ensures that Parkinson's law-'(administrative) work expands so as to fill the time 
available for its completion'-will not creep up on them. The scientific community needs to perceive a DG as 'one of us'; the very few that did not have a stellar scientific CV had to work hard to earn its respect.

\section{A Path-Dependent Collaborative Regime}

CERN began as a collaborative proposition. Collaboration remains at its heart today. The language of collaboration is deeply entrenched in CERN's structures and semantics. CERN's entire modus operandi belies the notion that science is essentially or even predominantly a competitive enterprise.

The genius of CERN's formula is that it does not deny the existence and propulsion power of competition between scientists, but that is has found a way of harnessing these competitive instincts within an overall framework of collaboration. In models of collaborative governance (e.g. Ansell and Gash 2008; Emerson and Nabatchi 2015), the essential fuel that makes collaborations succeed is a composite of felt interdependence around a task or ambition that is salient to all the parties involved; the growth of trust and alignment of motivations between participants that may have widely varying perspectives, responsibilities and values and are subject to their own governance structures and accountabilities; commitment to a process of joint deliberation that they consider fair, safe and effective in forging paths towards concerted action; and eventually a generative cycle of trust-building begetting joint action that produces tangible benefits to all which in turn increases the appetite for continued collaboration. The story of CERN that we have told in this chapter refers to each of these elements.

In addition, however, we should consider the important role of path dependencies that started to happen from the early 1960s on and were brought to a new level once the LHC project had begun and eventually produced the results that turned CERN into a near-mythical institution. The OECD's (2014: 63) analysis of CERN's impacts on innovation picks up on this point:

CERN's network of institutional and personal contacts played a critical role in catalysing R\&D, and in overcoming difficulties in meeting cost and schedule goals. To some extent, the network is there simply because of the passage of time (the institutions concerned have been interacting for sixty years). It is true, as well, that national research organisations receive 
their funds from the same agencies that finance CERN, so that the linkages emerge naturally during the elaboration of national science policies.

Once the participating nations decided to pool their resources in this domain of science and kept at it for over a decade, this changed the incentive structures of the next generations of high-energy physicists and institutions. There was now this unique common pool resource without which the experiments that needed to be done could not be performed. As similar accelerators in the United States and Japan closed down in the 1960s-1980s or were never built, there were no alternatives left, thus raising the costs of exiting from the collaboration (or of not entering it in the first place). Once thought of as a mere resource, CERN became an intellectual 'hub' and a source of professional identity, further increasing its professional centrality, the attractiveness of membership and thus the centripetal pull of its resource claims.

\section{A Case in Point: The Large Hadron Collider Project}

Gillies' (2018) assessment of CERN's crowning achievement reflects the contemporary consensus within and far beyond the global network of scientific contributors to and users of CERN's technology and data:

CERN's Large Hadron Collider is a triumph of human ingenuity. It has pushed technology to new and hitherto unimaginable limits. Far from struggling more than one particle collision per bunch crossing - a scenario feared when the LHC was first proposed, the experiments are dealing with dozens. The LHC produces close to a billion collisions in each detector per second, and processes have been perfected to sort out those that might contain interesting physics.

Key to the success of the LHC accelerator and detectors are the organizational capacity and performance standards that have evolved within CERN. The high-energy physics community 'self-organized' in a remarkable way from the early days of the LHC project. In the years leading up to the decision to go for the LHC, the CERN community faced a stark choice: the next step for high-energy physics after the Large ElectronPositron collider (that was in operation between 1989 and 2000) would ideally be a linear electron-positron collider, but nobody knew how to 
build it. The alternative was to build a hadron collider, but nobody could build the requisite detector for catching the data it would generate. From these two 'impossible' options, the community chose the second. After years of groundbreaking R\&D-work, the gamble payed off.

The LHC Committee (LHCC), a peer-review committee consisting of independent scientists, was set up in 1992 and continues to shape the experimental LHC program and provide stewardship of it. It advises on directions, monitors progress of the experiments and assesses the credibility of experimental schedules. It reports to the Directorate and Council. Although the LHCC reports 'up', it also interacts closely with the seven multinational experimental collaborations that have formed around the LHC.

Each experiment is run by collaborations of scientists from institutes all over the world. All experiments use detectors to analyse the myriad of particles produced by collisions in the accelerator, but each has its own sets of detectors and therefore data to work with. Though each experiment to some degree pursues distinct questions that emerge from scientific debates among the participating scientists, the experiments also compete on as well as cross-validate one another's observations on the big-ticket aims of CERN (i.e. discovering the Higgs boson).

In general, the LHCC's advice is accepted by the collaborations, precisely because in case of disagreements it offers an arena for open and robust debate. Trust in the integrity of its processes thus mitigates conflicts that could otherwise disrupt and delay the joint efforts (Engelen 2012).

The seven experimental collaborations - the largest of which consist of more than a thousand members hailing from dozens of different institutes and supported by dozens of funding agencies-organize themselves but adhere to a generic structure agreed with CERN. The collaborations were underpinned by memoranda of understanding (MoUs). Although not legally binding, these documents were signed between CERN and the collaborating institutes and were essential in agreeing on the contributions and long-term commitments from each of the institutes, including CERN, and then for monitoring that the various partners delivered on these commitments.

These MoUs also formed the bedrock upon which the worldwide LHC Computing Grid (wLCG) was founded. The wLCG forms the essential data-analytic support structure necessary to process the massive amounts of data generated by the experiments conducted in the LHC. 
It was not until relatively late after LHC approval that it was realized that the computing effort required for processing the LHC data would need a highly innovative approach and would also require very substantial investment, both at CERN and worldwide. The MoUs, drafted at CERN's legal department and signed by delegates from the participating institutions with appropriate mandates, were particularly important as a way of communicating with the national funding agencies providing the all-important financial footing of the collaborating partner institutes and institutions.

Resources review boards (RRBs) were set up for each experiment and continue to shadow them throughout their lifetime. Their membership consists of one representative from each funding agency with the experiment's management in attendance. They are chaired by CERN's Director of Research and provide the interface between the experiments, the national funding agencies and CERN. During the long years of constructing the experiments, the RRBs were particularly crucial in securing adequate and continuing funding.

The RRBs monitored progress in light of available (or pledged) resources. For the large general-purpose experiments in the LHC, ATLAS and CMS, a ceiling of 475 million Swiss francs for each was set by the CERN Directorate as the maximum investment costs. Capping investment in this fashion proved to be a great incentive for the experimental collaborations to be as resourceful and realistic as possible. The term 'descoping' was invented to denote the process of giving up some (redundant) functionality in order to save costs. In case of unavoidable additional expenditure, the RRBs provided the platforms for assessment and for reaching agreements on additional pledges from the funding agencies and from CERN and for postponing certain investments that were less urgent than others.

This process was, not surprisingly, punctuated by conflict. For example, the management and operating costs for the experiments were not always readily accepted or even understood by some of the funding agencies. In order to make the cases as convincing as possible, a Scrutiny Group reporting to the RRBs was formed. The experiments provided detailed information on the costs incurred (retrospectively) and made estimates for the next year. After scrutiny, these costs were then shared between the participants. The discussions were often emotional. 'Users' are not used to paying for things at CERN, and yet CERN could not and would not provide financial carriage of the entire experimental program in addition 
to the investments (and running costs) for its accelerator complex. The RRBs provided crucial platforms buffeted by clear rules of engagement for working through these tensions and laying the foundations for costsharing agreements between funding agencies (Engelen 2012).

\section{Sustaining the Mystique: \\ Challenges of Consolidation}

As Höne and Kurbalija (2018: 70) note, CERN's governance structures and practices allow for its projects to originate from and be driven by the needs and ambitions of science, while allowing for compromise on the basis of political and resource considerations. This track record of achieving workable balances will be put to the test in the coming decades, in a European and global environment that is much more turbulent and less favourable than it was in the decades when the LHC came to fruition. Womersley (2019) reflects the ambivalence, noting that as 'the archetype of intergovernmental organization in science, [CERN] offers great stability in the face of political upheavals such as Brexit', at the same time admonishing the CERN community that 'its challenge today is to think outside the box'.

The history of CERN buffets Mazzucato's (2018) celebrated thesis that only the state-in CERN's case a growing coalition of states represented in its Council and Finance Committee-has the required capital and persistence to fund the kind of fundamental research that produces the knowledge infrastructure for highly impactful and commercially viable innovations. So far, so good. Yet, if iconic organizations (Bekaert et al. 2016) are to retain their status as institutions, they need to be able to continuously challenge the very 'way we do things around here' that has produced their past successes. Indeed, Selznick (2000) reminds us that to maintain viable, an institution will have to adapt to maintain its fruitful relation with its ever-changing environment without forgetting its founding mission, shedding competitive advantage or effectiveness, suffering identity damage-while maintaining its moral integrity. But how to accomplish this when their past and present are regularly glorified both externally and internally? As organizations institutionalize, their character and modus operandi become imbued with value. This begets stability but loses flexibility (Selznick 1957: 7).

How then, in this era of the 'Fourth Industrial Revolution' and the 'Asian Century', can an international knowledge institution such as 
CERN overcome this twin threat of complacence and rigidity? Ansell et al. (2015) propose that institutional leaders should pursue a strategy of dynamic conservatism in which the organization engages in 'pre-emptive adaptation' to foreseeable and consequential changes in its operating as well as its political environment.

This is highly apposite to CERN. In today's era of 'monitory democracy' (Keane 2018) and public disenchantment with many public institutions, the benign opinion climate surrounding CERN cannot be taken for granted. Media and other watchdogs may change their tune on CERN. As one pre-Higgs Boson critic (O’Neill 2008) observed astutely:

The media would rather talk excited gibberish about the LHC than ask hard questions about support for science in a democratic society, or the proper priorities for research in physics. The CERN scientists are happy to meet the media's demand for hyperbole, as it obscures the most important questions about funding for CERN. This should not sound too negative. The LHC is a magnificent human achievement, a great feat of collaboration and logistics, and it will surely bring fascinating scientific advances. But, in a sane democratic society, the media and the scientists themselves need to do a better job about talking sensibly about its purpose, goals and justification.

CERN wants to remain a nimble, cooperative, science-driven international organization. ${ }^{l}$ At the same time, it has to adapt to an ever more dynamic scientific and science policy landscape and to a more complex geopolitical picture in which the European ideals and identities that helped create and sustain CERN have come under pressure. With large states such as Russia showing an interest to be included as members, the CERN Council has to weigh the extent to which such new applicants not only merit inclusion on the grounds of scientific capabilities and resources, but are likely to fit its governance culture.

Meanwhile, other large and scientifically ambitious states such as Japan, China and the United States are currently not bound into CERN by membership status (if they were to join, through the size of their GNP's they would dominate the budget vastly and throw the balanced system of governance out of joint). This being the case, some are developing their own plans for the next big post-LHC facility, effectively challenging CERN's de facto monopoly in advanced particle physics research. This only ups the ante for one of the major challenges to CERN in the coming decade: to build and sell its own business case for the next mega-facility, 
whose scale and time horizon surpass anything the organization has ever tried before.

If it is to retain its iconic status, CERN will need to produce new quantum leaps in physics and technology in order to stay ahead of the pack, sustain its position as an icon of global science and deliver 'public value' above and beyond satisfying scientific curiosities. For that to happen, it needs to once again make strategic choices about its future research directions, bring its stakeholders along on that journey and secure very large amounts of money for very long periods of time. Given how many resources, careers and reputations are invested in its path leading up to the present, asking and answering these questions will require strategic leadership of the highest order. It will come down to the interplay between Directorate, Council, the CERN Community and its member states and stakeholders to rethink, retain and renew CERN's way of operating without compromising its core mission and values which have served it so well in its first six decades.

\section{Questions For Discussion}

1. Discovering what the universe is made of is just about the most elusive mission that one can think of for any organization. What role did this lofty, elusive and super long-term ambition play in the institutionalization of CERN?

2. How did CERN manage to get government policymakers from its member states to keep funding the boundless ambitions of its scientists for over nearly 70 years?

3. What risks did CERN take in pushing for the construction of the Large Hadron Collider, and how did it manage these risks?

4. What role did leadership play in building CERN into the international scientific institution it is today, who exercised this leadership and what forms did it take?

5. If you were asked to advise about the setting up of a new long-term, international scientific laboratory to be underpinned fully or mostly by public funding, what lessons from the CERN experience do you think are crucial to incorporate into that advice? 


\section{Note}

1. In a break with tradition, CERN's current Director-General, Fabiola Gianotti was reappointed for another 5 years in her position after reapplying for it when her term as DG expired (Banks 2019). She envisages a post-LHC world in which CERN is no longer the only game in town. She realizes that CERN cannot afford to drag its feet in pushing for the next frontier: 'With CERN, Europe has regained leadership in fundamental physics at the energy frontier and also in the advanced technologies that are needed to do these experiments... [I]t would be a real pity if that leadership were to go elsewhere in the world' (quoted in Sample 2019).

\section{REFERENCES}

Ansell, C. K., Boin, A., \& Farjoun, M. (2015). Dynamic conservatism: How institutions change to remain the same. Research in the Sociology of Organizations, 44, 89-119.

Ansell, C. K., \& Gash, A. (2008). Collaborative governance in theory and practice. Journal of Public Administration Research and Theory, 18(4), 543-571.

Banks, I. (2019, November 8). Fabiola Gianotti to remain CERN boss until 2025. Physicsworld. https://physicsworld.com/a/fabiola-gianotti-to-remaincern-boss-until-2025/. Accessed 10 February 2020.

Bekaert, X., Jonk, G., Wibbens, P., \& Raes, J. (2016). Iconic: How to Create a Virtuous Circle of Success. London: LID Publishing.

Birnholtz, J. (2008). When authorship isn't enough: Lessons from CERN on the implications of formal and informal credit attribution mechanisms in collaborative research. Journal of Electronic Publishing, 11(1). http://dx.doi.org/ 10.3998/3336451.0011.105.

Cogen, M. (2016). An Introduction to European Intergovernmental Organisations. Abingdon: Routledge.

Emerson, K., \& Nabatchi, T. (2015). Collaborative Governance Regimes. Washington: Georgetown University Press.

Engelen, J. (2012). The Large Hadron Collider project: organizational and financial aspects (of physics at the terascale). Philosophical Transactions of the Royal Society a: Mathematical, Physical and Engineering Sciences, 370(1961), 978-985.

Gillies, J. (2018). CERN and the Higgs Boson: The Global Quest for the Building Blocks of Reality. London: Icon Books.

Gillies, J., \& Cailliau, R. (2000). How the Web was Born. Oxford: Oxford University Press. 
Goetz, K., \& Patz, R. (2017). Resourcing international organizations: resource diversification, organizational differentiation, and administrative governance. Global Policy, 8(5), 5-14.

Goodsell, C. (2011). Mission mystique: Strength at the institutional center. American Review of Public Administration, 41(5), 475-494.

Hale, T., \& Held, D. (2017). Beyond Gridlock. Cambridge: Polity Press.

Hofstede, G. H. (1991). Cultures and Organizations: Software of the Mind. New York: McGraw-Hill.

Höne, J., \& Korbalija, J. (2018). Accelerating basic science in an intergovernmental framework: Learning from CERN's science diplomacy. Global Policy, 9(Suppl 3), 67-72.

Keane, J. (2018). Power and Humility: The Future of Monitory Democracy. Cambridge: Cambridge University Press.

Lucibella, M. (2014). CERN: 60 years of collaboration. APS Physics, 23(8), 4-7. Mazzucato, M. (2018). The Entrepreneurial State. London: Penguin.

O’Neill, M. (2008, 17 September). Politics of proton smashing. New Statesman. https://www.newstatesman.com/international-politics/2008/09/physicslhc-cern-scientific. Accessed 10 February 2020.

OECD. (2014). The Impacts of Large Research Infrastructures on Economic Innovation and on Society: Case Studies at CERN. Paris: OECD.

Pestre, M. (1988, November). The CERN System, its Legislative and Executive Arms and some global statistics on how it functioned. Geneva: CERN https://cds.cern.ch/record/720698/files/CERN-CH-27.pdf. Accessed 18 March 2020.

Robinson, M. (2019). The CERN community: A mechanism for effective global collaboration? Global Policy, 10(1), 41-51.

Sample, I. (2019, February 23). Fabiola Gianotti: 'There is nothing more rewarding than discovering a new particle.' The Observer. https://www.the guardian.com/science $/ 2019 / \mathrm{feb} / 23 /$ fabiola-gianotti-interview-director-gen eral-cern-particle-physicist-large-hadron-collider. Accessed 10 February 2020.

Schulman, P. (1980). Large-Scale Policymaking. New York: Elsevier North Holland.

Selznick, P. (1957). Leadership in Administration: A Sociological Interpretation. New York: Harper \& Row.

Selznick, P. (2000). On sustaining research agendas: Their moral and scientific basis. Journal of Management Inquiry, 9(3), 277-282.

Starkman, G. (2018, May 23). The Standard Model of particle physics: The absolutely amazing theory of almost everything. The Conversation. https:// theconversation.com/the-standard-model-of-particle-physics-the-absolutelyamazing-theory-of-almost-everything-94700. Accessed 10 February 2020. 
Verbeek, B. (2009). Leadership of international organizations. In J. Kane, H. Patapan, \& P. 't Hart (Eds.), Dispersed Democratic Leadership: Origins, Dynamics, and Implications (pp. 235-255). Oxford: Oxford University Press. Womersley, J. R. (2019, May 8). Building scientific resilience. CERN Courier. https://cerncourier.com/a/building-scientific-resilience/. Accessed 10 February 2020.

Open Access This chapter is licensed under the terms of the Creative Commons Attribution 4.0 International License (http://creativecommons.org/licenses/ by $/ 4.0 /)$, which permits use, sharing, adaptation, distribution and reproduction in any medium or format, as long as you give appropriate credit to the original author(s) and the source, provide a link to the Creative Commons license and indicate if changes were made.

The images or other third party material in this chapter are included in the chapter's Creative Commons license, unless indicated otherwise in a credit line to the material. If material is not included in the chapter's Creative Commons license and your intended use is not permitted by statutory regulation or exceeds the permitted use, you will need to obtain permission directly from the copyright holder.

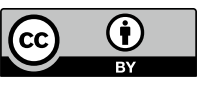

